\title{
Toxicity of the Extracellular Phase of Prymnesium parvum Cultures
}

\author{
BY J. YARIV AND S. HESTRIN \\ Department of Biological Chemistry, Hebrew University, Jerusalem, Israel
}

(Received 7 July 1960)

\begin{abstract}
SUMMARY
Cytotoxic material ('prymnesin') excreted into the growth medium by the phytoflagellate Prymnesium paroum was partially purified and crudely characterized. It proved to be a highly potent haemolysin; its solubility properties and some other characteristics are those of a lipid, perhaps a saponin. The high haemolytic activity which characterized the toxin was often also accompanied by a high ichthyotoxic activity. A method of locating haemolytic activity in a paper chromatogram is described. Fish were killed not by prymnesin alone, but were rendered highly susceptible to prymnesin poisoning by a range of cofactors: streptomycin sulphate, calcium chloride, magnesium chloride. Ichthyotoxicity in cofactor + prymnesin systems conformed within a wide concentration range to the relationship : $a \times b=Q$, where $a$ is a prymnesin concentration, $b$ a minimum concentration of cofactor which elicits a lethal effect in presence of $a$, and $Q$ is a cofactor-specific constant. The recognition of this relationship has enabled a sensitive assay to be developed. Practical implications are discussed and the hypothesis proposed that prymnesin acts on fish by inducing a state of abnormal permeability of the gill.
\end{abstract}

\section{INTRODUCTION}

Outbreaks of mass mortality among gill-breathing inhabitants of pond waters have been associated with blooms of a toxigenic phytoflagellate Prymnesium paroum Carter (Otterström \& Steeman-Nielsen, 1940; Reich \& Aschner, 1947; Shilo \& Aschner, 1953; Yariv, 1955, 1958; Shilo \& Rosenberger, 1960). Severe losses are inflicted on the carp industry of Israel by this agent. The present communication describes a procedure for the recovery of stable and partially purified toxic material 'prymnesin' from the culture fluid of $\boldsymbol{P}$. paroum cultures, describes some general properties of the preparation and discusses methods for its assay.

\section{METHODS}

Cultivation of Prymnesium parvum. Pure cultures were kindly made available to us by Mrs Mira Shilo. Strain no. 1 was originally isolated in Israel from fish ponds by Reich \& Kahn (1954) and strain no. 2 by Droop (1954) in Scotland from supralittoral pools.

Pure cultures were made in a medium composed of $0.02 \%(w / v)$ liver extract (Difco), 0.02\% (w/v) Bacto-tryptone (Difco) and $10 \%(w / v)$ sea water in distilled water in $500 \mathrm{ml}$. conical glass flasks maintained under fluorescent lamps at $20^{\circ}$. 
A 2-week-old culture was used in the proportion of 1:10 for inoculum. Largescale preparations were made from samples of pond water (batch size about 50 l.) which had been transferred during prymnesium bloom to a tank which was maintained at ambient temperature $\left(10-25^{\circ}\right)$ under fluorescent lighting for 1 to 2 weeks, in which time the toxic activity reached its peak.

\section{Detection and measurement of haemolytic activity}

Reference standard. Digitonin (Merck, C. P.) served as a standard for reference; the stock solution was at a concentration of $0.026 \%(w / v)$ in water. At a dilution of $1 / 200$ in isotonic sodium chloride, this effected $50 \%$ lysis of bovine erythrocytes within $45 \mathrm{~min}$. in conditions of a standard assay described below.

Preparation of samples for assay. Samples to be assayed were brought to $\mathrm{pH} \mathrm{5.0}$ and to isotonic salt concentrations. Extracts of dry prymnesin preparations were prepared by either of the following methods. (a) Sample (about $2 \mathrm{mg}$.) was moistened with a drop of 0.1 M-sodium hydroxide and suspended in $10 \mathrm{ml}$. water. The suspension was cleared by centrifugation; the supernatant fluid was immediately brought to pH 3-4 with dilute hydrochloric acid, whilst the sediment was extracted again as before. The extracts were pooled, the $\mathrm{pH}$ adjusted and brought to a known total volume and to appropriate salt concentration. (b) Sample was stirred with successive portions of methanol until all the haemolytic activity had been taken into solution. Extracts in methanol were diluted at least 1/100 with buffered saline before assay.

Standard assay system. Since prymnesin often lost activity rapidly at $\mathrm{pH}>\mathbf{5}$ (see Results), assays were performed in acidified blood. As bovine erythrocytes withstand acid conditions better than do sheep erythrocytes, they were used in preference to the latter. The blood was taken into an equal volume of isotonic salt solution (0.078 M-sodium chloride, $0.042 \mathrm{M}$-sodium citrate, $0.114 \mathrm{M}$-glucose; $\mathrm{pH} \mathrm{6.1)}$ and stored at $4^{\circ}$. Before assay, stored red cells were washed 3 times in the cold with 10 vol. of buffered saline (0.130 M-sodium chloride adjusted to $\mathrm{pH} \mathrm{5.0}$ with $0.020 \mathrm{~m}$-citrate). The assay system consisting of toxin with approximately $0.4 \%$ $(\mathrm{v} / \mathrm{v})$ bovine erythrocytes in buffered saline at $\mathrm{pH} 5.0$ was incubated for $45 \mathrm{~min}$. at $\mathbf{8 5} \pm \mathbf{0 . 5 ^ { \circ }}$.

The degree $(\%)$ of haemolysis was determined colorimetrically, essentially as described by Collier (1951). The values of optical density were respectively 340 and 190 (galvanometer units measured in a Klett galvanometer with filter 54) for 0 and $100 \%$ haemolysis. The decrease of optical density was closely proportional to the $\%$ haemolysis at all values of the latter.

A unit of haemolytic activity was defined as that amount of prymnesin which effected $50 \%$ lysis of bovine erythrocytes in one $\mathrm{ml}$. of standard assay system. This unit is equivalent to $1.3 \mu \mathrm{g}$. digitonin. Figure 1 shows that in the range 0.8-1.2 units there was an almost linear relationship between concentration of haemolysin and $\%$ haemolysis. Titration within an accuracy of $\pm 7 \%$ generally required 30 units toxin in a solution at a concentration of at least 3 units $/ \mathrm{ml}$.

Test of haemolytic activity on paper. Loci of haemolytic activity were detected in paper chromatograms by means of an erythrocyte spray $(2 \%, \mathrm{v} / \mathrm{v}$, bovine erythrocytes in 0.187 M-sodium chloride +0.020 M-sodium phosphate; $\mathrm{pH} \mathrm{6.8).} \mathrm{This}$ was applied to the vertically suspended paper from a horizontal direction, starting from the top and working downwards in such a way as to leave a dry area at the 
top of the paper strip while excess of fluid accumulated at the bottom. While the strip dried in air (10-20 min.), fluid flowed through it in an upward direction. Whilst such a flow did not cause migration of erythrocytes, any haemoglobin released by haemolysis was moved by the current and formed a dark spot in the region above the haemolytic locus; a bleached area remained below the dark spot. Certain non-haemolytic hydrophobic substances caused the erythrocytes to aggregate with attendant whitening or darkening of the locus (Table 1). However, as such changes were not accompanied by migration of haemoglobin, they were readily distinguished from a true haemolytic action. A reaction observed by Heftman \& Hayden (1952) at sapogenin loci on paper is believed by us to have been of this non-specific kind and to have been interpreted erroneously as a sign of haemolytic activity.

Table 1. Specificity of the haemolysis reaction on paper

Substance*

Digitonin

Prymnesin:

Lysolecithin

Saponin

Digitogenin

Cholesterol

Kryptogenin acetate

Tristearin
Solvent

Methanol
n-Propanol + water $(1+1, v / v)$
Water
Methanol
Methanol
Methanol
Ethanol + chloroform $(1+1, v / v)$
Ethyl ether

$\begin{array}{cc}\text { Reaction } \dagger & \left.\begin{array}{c}\text { Minimum } \\ \text { reactive } \\ \text { dose }(\boldsymbol{\mu g})\end{array}\right) \\ h & 0 \cdot 8 \\ h & 1.5 \\ h & 5 \\ h & 40 \\ n h & 8 \\ n h & 8 \\ n h & 16 \\ n h & 100\end{array}$

* Lysolecithin was kindly supplied by Mr G. Rimon. Digitogenin and kryptogenin acetate were made available through the courtesy of Professor C. Djerassi.

$\dagger$ A haemolytic reaction is designated $h$ and a non-specific colour change by $n h$.

$\mp$ Fraction $\mathbf{X b}$ (see text) was used for this experiment.

\section{Measurement of ichthyotoxic activity}

Fish. Gambusia minnows (25-40 mm. long) collected from pools in Beisan Valley, Israel, served as the test organism. The animals were maintained in the laboratory in tanks of tap water under a gentle stream of air.

Standard assay system. Ichthyotoxicity was measured on the basis of the ability of prymnesin to enhance the susceptibility of fish to the lethal action of streptomycin. Groups consisting of five fish were immersed in beakers at $20^{\circ}$ into $20 \mathrm{ml}$. of solution containing prymnesin, sodium bicarbonate at $5 \mathrm{~mm}$ and streptomycin sulphate at $2.0 \mathrm{~mm}(0.1 \%)$ in distilled de-ionized water. The solution was adjusted to $\mathrm{pH} 8.0$ with $\mathrm{NaOH}$ and held within $\pm 0.2 \mathrm{pH}$ units throughout the assay. The 'fish unit' of toxin was defined as that minimum amount of prymnesin/ml. which killed all five minnows present in $20 \mathrm{ml}$. of standard solution containing streptomycin sulphate at pH 8.0 during $8 \mathrm{hr}$. at $20^{\circ}$. In the conditions of this assay, streptomycin sulphate alone or prymnesin alone did not kill any of the fish. The titrations of toxicity were reproducible within $\pm 10 \%$. A total of about 100 fish was generally used per titration.

Ichthyotoxin preparation. Except as otherwise indicated, prymnesin at stage $\mathbf{Z}$ of purification (see under Results) was used in experiments on ichthyotoxicity. Stock solutions ( $\mathrm{pH} 4 \cdot 0$ ) in water were stored at $6^{\circ}$. 


\section{RESULTS}

Supernatant fluids from pure cultures of Prymnesium parvum increased in toxicity during the first 2 weeks. Haemolytic titres reached 6-30 units $/ \mathrm{ml}$. and ichthyotoxic titres about 6 units/ml.

\section{Purification of toxic principles}

A pure culture (strain no. 1) of Prymnesium parvum with an activity of 16 haemolytic units/ml. at 16 days was cleared by centrifugation $(12,000 \mathrm{rev} / / \mathrm{min}$. in a Sharples centrifuge) and the culture fluid brought to $\mathrm{pH}$ 10-11 with conc. sodium hydroxide, added with vigorous stirring. A flocculent precipitate, consisting mainly of magnesium hydroxide, was allowed to sediment $(1 \mathrm{hr}$.), packed down by centrifugation and dissolved in $\mathrm{N}$-hydrochloric acid $(100 \mathrm{ml}$.). The solution ( $\mathrm{pH} \mathrm{2-3)}$ was dialysed against $0 \cdot 1 \mathrm{~mm}$-hydrochloric acid through cellophan at $6^{\circ}$ for 3 days. On freeze-drying the material remaining in the dialysis sac (dialysand) $140 \mathrm{mg}$. of a fluffy, somewhat hygroscopic powder (Z) was obtained. About $50 \%$ of the original haemolytic activity was recovered in this fraction. Its haemolytic and ichthyotoxic activity remained unchanged during prolonged storage (1 year at $-15^{\circ}$ in an evacuated ampoule). Product $\mathrm{Z}$ was converted into a granular product (Y) by grinding under cold absolute acetone. Solution of this material in $50 \mathrm{ml}$. methanol gave on evaporation under reduced pressure $12.5 \mathrm{mg}$. of a slightly yellow powder (X) having an activity of 4800 haemolytic units/mg. A large-scale operation conducted on a monoalgal rather than pure culture is summarized in Table 2.

Table 2. Purification and resolution of active principle in supernatant fuid of monoalgal Prymnesium parvum culture

Purification procedure was essentially as that described in the experiment with a pure culture (see text).

\begin{tabular}{|c|c|c|c|c|}
\hline Fraction* & $\begin{array}{l}\text { Recovery of } \\
\text { haemolytic } \\
\text { activity } \\
\text { (\% of } \\
\text { starting } \\
\text { material) }\end{array}$ & $\begin{array}{l}\text { Dry weight } \\
\text { (mg.) }\end{array}$ & $\begin{array}{c}\text { Haemolytic } \\
\text { activity } \\
\text { (units/mg.) }\end{array}$ & $\begin{array}{l}\text { Ichthyotoxic } \\
\text { activity } \\
\text { (units/mg.) }\end{array}$ \\
\hline Culture fluid & 100 & $10^{\circ}$ & 0.5 & $0 \cdot 15$ \\
\hline $\mathbf{Z}$ & 78 & 299 & 1240 & 400 \\
\hline $\mathbf{Y}$ & 78 & 204 & 1640 & 530 \\
\hline $\mathbf{X}$ & 78 & 52 & 6700 & 1900 \\
\hline $\mathbf{X}_{\mathbf{a}}$ & 6 & 4 & 6400 & - \\
\hline $\mathbf{X} \mathbf{b}$ & 68 & 44 & 6700 ' & 1700 \\
\hline
\end{tabular}

* Letter symbols are used to designate successive steps in purification as described in the text.

Resolution of toxin in a propanol+water system. Product $\mathbf{X}$ was washed in absolute $n$-propanol $(20 \mathrm{ml}$.) without loss of activity and then dispersed in $n$ propanol + water $(90+10, \mathrm{v} / \mathrm{v})$. About $11 \%$ (fraction $\mathrm{Xa}$ ) of the total activity was taken into solution by this solvent. The residue was dispersed in $30 \mathrm{ml}$. of $n$-propanol + water system $(50+50, v / v)$, to afford a solution which was cleared by centrifugation and then concentrated under reduced pressure with successive additions of absolute $n$-propanol. On evaporation of the solvent, $7 \cdot 4 \mathrm{mg}$. of a light yellow powder $(\mathrm{Xb})$ were recovered. This contained most of the original activity at 
5600 haemolytic units/mg., a value nearly eight times that found with digitonin in the standard assay conditions.

Chromatographic resolution of toxin on cellulose. Suitable solvent systems applied on a paper sheet (Table 3) or on a cellulose column (Fig. 2) resolved the activity of product $Z$ into at least two components. An all-glass column $(600 \mathrm{~mm}$. long and $35 \mathrm{~mm}$. in diameter) contained Whatman's Ashless Cellulose Powder pretreated as recommended by Stoll \& Kreis (1951). The developing system was ethyl acetate + $n$-propanol + water $(8+2+3, v / v)$. Fraction $Z$ of prymnesin $(50,000$ units contained

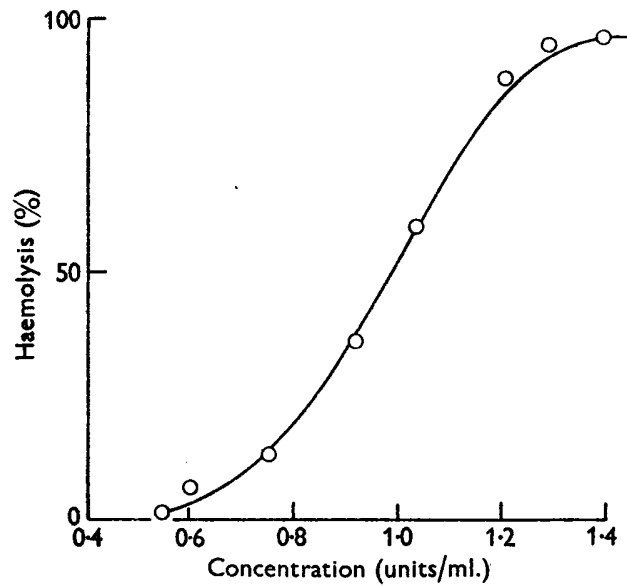

Fig. 1. Concentration effect function of prymnesin.

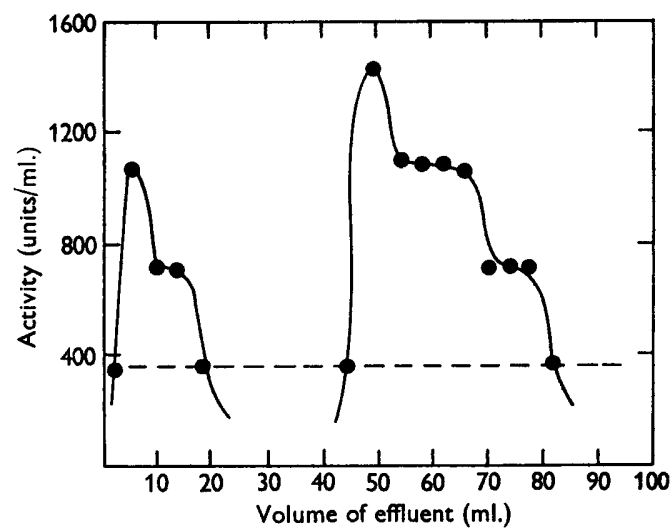

Fig. 2. Chromatographic resolution of prymnesin on a cellulose column.

Table 3. Mobility of various haemolysins on paper

Whatman no. 1 paper was used with a development time of $15 \mathrm{hr}$. at room temperature.

Solvent system $(v / v)$
$n$-Amyl alcohol + acetic acid + water $(7+8+10)$
$n$-Butanol + water $(1+1)$
Ethyl acetate $+n$-propanol + water $(8+2+3)$
$n$-Amyl alcohol + $n$-butanol + water $(1+4+5)$
Ethyl acetate + $n$-propanol + water $(7+5+10)$
n-Butanol saturated with water

$\begin{array}{lc}\text { Substance } & \text { Appropriate } \boldsymbol{R}_{\boldsymbol{f}}^{*} \\ \text { Prymnesin } & 0.06 ; 0.17 \\ \text { Prymnesin } & 0 \cdot 18 \\ \text { Prymnesin } & \mathbf{0 . 2 1} ; \mathbf{0 . 3 4} \dagger \\ \text { Prymnesin } & \mathbf{0 . 4 5} \\ \text { Prymnesin } & 0.90 \\ \text { Lysolecithin } & 0.68 \\ \text { Digitonin } & 0.05 \\ \text { Prymnesin } & 0.05\end{array}$

* Where toxin was resolved into components, the $\boldsymbol{R}_{f}$ value of the major component is given in bold figures.

$\uparrow$ Ninhydrin-positive substances (test performed as by Berry \& Cain, 1949) in the sample were resolved by this system and gave $R_{f}$ values of $0 \cdot 00,0 \cdot 06,0 \cdot 15$. At the two haemolytic loci, however, no substance which gave a positive reaction with ninhydrin was detected.

in $60 \mathrm{mg}$.) was applied in the aqueous phase of the solvent and developed in the organic phase. Successive $4.0 \mathrm{ml}$. fractions of effluent were examined for activity $>\mathbf{3 6 0}$ units $/ \mathrm{ml}$. by paper test. A fast-moving fraction (corresponding to $\mathrm{Xa}$ in Table 2) represented $20 \%$ of the total activity put in the column; a slow-moving fraction (corresponding to $\mathrm{Xb}$ in Table 2 ) represented $>60 \%$ of the total activity 
applied to the column. The furfural test (Feigl, 1954) for carbohydrate in both these fractions was positive. The minimum haemolytic activity which was detectable by the analytical procedure used is indicated in the figure by the broken horizontal line. A major (slow) component in product $\mathrm{Z}$ had the same $\boldsymbol{R}_{f}$ value as the active compound found in the $\mathbf{X b}$ fraction described above. The $\boldsymbol{R}_{f}$ value of the minor (fast) component of product $\mathrm{Z}$ corresponded to the active compound in the $\mathbf{X a}$ fraction.

\section{General properties of toxin}

Some solubility properties of the prymnesin are given in Table 4. Information about keeping qualities of this preparation, and on behaviour with precipitating agents and adsorbents as well as miscellaneous other features, is collected in Table 5.

\section{Table 4. Solubility of prymnesium haemolysin in organic liquids}

A sample (2 mg.) of prymnesin purification $Z$ was stirred with $0.2 \mathrm{ml}$. solvent, centrifuged, and the supernatant fluid then tested for haemolytic activity.

Haemolytic activity

1000 units or more $/ \mathrm{ml}$.

Methanol, pyridine*, $n$-butanol (sat. with water), $n$-propanol + water $(1+1, v / v)$, e-systems $\uparrow$.
200 units or less $/ \mathrm{ml}$.

n-Propanol, $n$-butanol, acetone, diethyl ether, light petroleum, ethyl acetate, ethyl acetate (sat. as to water), benzene, chloroform, carbon tetrachloride.

* Activity in pyridine declined rapidly.

$\dagger e$-systems $=$ aqueous and organic phase of ethyl acetate $+n$-propanol + water $(8+2+3, v / v)$.

Prymnesin solutions (10-100 units $/ \mathrm{ml}$.) in water showed a marked decrease in titre when kept for $60 \mathrm{~min}$. at $35^{\circ}$. When solutions which had been partially inactivated by such treatment were subsequently brought to $\mathrm{pH} 4 \cdot 0$, their original activity was rapidly restored.

Relation of ichthyotoxic and haemolytic activities. Though the ratio of haemolytic activity to ichthyotoxic activity in a given preparation of prymnesin remained roughly constant throughout purification (Tables 2,5 ), wide variations in ratio were encountered between different batches of toxin. Several preparations which exhibited high haemolytic activity indeed had no apparent ichthyotoxicity.

Observations on ichthyotoxicity of roater samples from pure cultures and from ponds during prymnesium bloom. As reported by Liebert \& Deerns (1920), Otterstrøm \& Steeman-Nielsen (1940) and Reich \& Aschner (1947), samples of water taken from ponds during prymnesium bloom were frequently but not invariably ichthyotoxic. When toxic samples were dialysed through cellophan $\left(72 \mathrm{hr} . ; 6^{\circ} ; \mathrm{pH} 4.0\right)$, the separated dialysate and dialysand had no lethal effect on fish, but were again toxic when pooled.

Passage through a cation-exchange column ( $\mathrm{H}^{+}$form of Amberlite IRC 50) abolished the ichthyotoxicity of pond-water samples. On elution of the column with $\mathrm{N}-\mathrm{HCl}$, material was recovered which conferred toxicity on dialysand prepared from a toxic water sample. The active factor in the eluate was not destroyed by ashing. Dialysand of toxic water samples formed a toxic system 


\section{Table 5. Influence of various treatments on cytotoxic activities of prymnesin}

Aqueous solutions contained 10-100 units prymnesin/ml.; solutions in organic liquids represented extracts of product $\mathrm{Z}$ at a concentration of about 1000 units $/ \mathrm{ml}$. The $\mathrm{pH}$ values of the aqueous solutions were adjusted with $\mathrm{HCl}$ to $\mathrm{pH} 0.0,4.0$ and 6.0 and with $\mathrm{NaHCO}_{2}$ to 8.0. Except as otherwise stated, all treatments tabulated below were performed at $25^{\circ}$ and lasted for 5 min.

\begin{tabular}{|c|c|c|c|c|c|}
\hline $\begin{array}{l}\text { Treat- } \\
\text { ment }\end{array}$ & $\begin{array}{l}\text { Tested property } \\
\text { or reagent }\end{array}$ & Solvent & Particulars of treatment & $\begin{array}{l}\text { Liquid } \\
\text { phase }\end{array}$ & $\begin{array}{c}\text { Solid } \\
\text { phase }^{2}\end{array}$ \\
\hline $\mathbf{1}$ & Storage & Water & $700 \mathrm{hr} . ; 6^{\circ} ; \mathrm{pH} 4$ & $100^{1}$ & * \\
\hline 2 & Storage & Water & 24 hr.; pH 4 & 100 & * \\
\hline $\mathbf{8}$ & Storage & Water & 24 hr.; pH 8 & $\mathbf{0}$ & * \\
\hline 4 & Thermostability & Water & $\begin{array}{l}15 \text { min.; } 98^{\circ} \text {; sealed vessel; } \\
\text { pH } 4\end{array}$ & 100 & $*$ \\
\hline $\mathbf{5}$ & Thermostability & Water & 15 min.; $98^{\circ}$ (boiling); pH 4 & $\mathbf{0}$ & $*$ \\
\hline 6 & Thermostability & n-Propanol & 15 min.; $94^{\circ}$ (boiling) & 100 & $*$ \\
\hline 7 & Thermostability & Methanol & 15 min.; $62^{\circ}$ (boiling) & 100 & $*$ \\
\hline 8 & Hot acid & Water & 15 min. ; $98^{\circ}, \mathrm{pH} 0$ & $\mathbf{0}$ & $0^{3}$ \\
\hline $\boldsymbol{9}$ & $\begin{array}{l}\text { Water/gas inter- } \\
\text { phase }\end{array}$ & Water & $24 \mathrm{hr}$; ; stream of $\mathrm{N}_{2} ; \mathrm{pH} 4$ & 60 & * \\
\hline 10 & Diffusibility & Water & $\begin{array}{l}72 \text { hr.; } 6^{\circ} \text {; cellophan mem- } \\
\text { brane; pH } 4\end{array}$ & 1004 & $*$ \\
\hline 11 & Cellulose & Water & $\begin{array}{l}\text { Paper (Whatman no. 1); } \\
\text { pH 4 }\end{array}$ & $\mathbf{8 0}$ & $70^{5}$ \\
\hline 12 & Ca phosphate & Water & $\begin{array}{l}15 \text { min.; Na-acetate } 5 \mathrm{~mm} \text {; } \\
\text { pH } 4\end{array}$ & $44^{6}$ & - \\
\hline 18 & $\mathrm{Mg}(\mathrm{OH})_{\mathbf{2}}$ & Water & 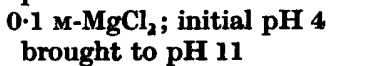 & $\mathbf{0}$ & $57^{7}$ \\
\hline 14 & $\left(\mathrm{NH}_{4}\right)_{2} \mathrm{SO}_{4}$ & Water & $6^{\circ} ; 0.24$ of sat.; pH 6 & $\mathbf{0}$ & $34^{8}$ \\
\hline 15 & Chloroform & Water & $6^{\circ}$; shaking; pH 4 & $0^{9}$ & $32^{10}$ \\
\hline 16 & $\begin{array}{l}\text { Cholesterol, ace- } \\
\text { tone or } n \text {-amyl } \\
\text { alcohol }\end{array}$ & Methanol & Reagent at $1 \%$ & 60 to 80 & -11 \\
\hline 17 & Diethyl ether & Methanol & Reagent at $1+1(v / v)$ & 36 & $42^{12}$ \\
\hline 18 & Petroleum ether & e-System ${ }^{18}$ & Reagent at $1+1(v / v)$ & 30 & $56^{12}$ \\
\hline
\end{tabular}

1 Values denoted by bold figures designate solutions that were tested also as to ichthyotoxic activity. In all these cases, ratio of haemolytic to ichthyotoxic activity was found not to have been altered significantly by the treatment in question.

Absence of precipitate formation is indicated by asterisk.

The precipitate was soluble in benzene.

1 The dialysate contained no activity.

- Methanol served as eluent.

- One ml. gel suspension (prepared according to Singer \& Kearney, 1950) was added to $10 \mathrm{ml}$. prymnesin solution. At $\mathrm{pH} 7-10$, little or no activity was adsorbed by this reagent.

7 Precipitate, consisting mostly of $\mathrm{Mg}(\mathrm{OH})_{2}$, was dissolved at $\mathrm{pH} 2$ (adjusted with $\mathrm{HCl}$ ) and dialysed before titration.

- The solid, being of low specific gravity, floated when the suspension was centrifuged; it was dissolved in water.

- Material in solution in the aqueous and in the organic phase of the solvent system was inactive.

10 The precipitate was collected at the chloroform-water boundary and dissolved in water after alkali treatment.

11 Precipitate formed with $1 \%$ reagent was not visibly dissolved and failed to release any activity into either methanol or $0.01 \mathrm{~m}-\mathrm{NaOH}$ in water. Increase of the concentration of reagent by several fold failed to elicit any further precipitation.

12 After removal of this precipitate, increase of the ether concentration to 2 vol. gave no further precipitate, but at 8 vol. a second precipitate formed with attendant disappearance of all activity from solution. The activity recovered on solution of the second precipitate into methanol represented $40-70 \%$ that in the original supernantant fluid.

1s e-system $=$ organic phase of ethyl acetate $+n$-propanol + water $(8+2+3, v / v)$. 
when it was mixed with $10 \mathrm{~mm}$-calcium chloride, $10 \mathrm{~mm}$-magnesium chloride or $2 \mathrm{~mm}$-streptomycin sulphate. In absence of dialysand the same solutions were innocuous to fish. Chlorides of monovalent cations $(\mathrm{Na}, K)$ at $20 \mathrm{~mm}$ were not toxic to the fish either in the presence or absence of dialysand. Similar results were also found when dialysed centrifugates from pure cultures of Prymnesium paroum were used for these experiments in the place of the pond-water dialysands.

\section{Effect of prymnesin on susceptibility of fish to poisoning by various compounds}

Toxicities of various inorganic salts and of streptomycin sulphate in the presence and absence of prymnesin are compared in Table 6.

The manner in which LD100 of selected compounds varied with the prymnesin concentration is shown by Fig. 3. These data fit a simple relationship: $a \times b=Q$, where $a$ is prymnesin concentration, $b$ is the minimum concentration of cofactor which elicits a lethal effect in the presence of $a$, and $Q$ is a cofactor-specific constant whose value defines the LD 100 of the cofactor for systems in which prymnesin is at unit concentration.

Cofactors all had practically the same LD100 values when measured in absence of prymnesin on prymnesin-pretreated minnows as when measured in the presence of prymnesin (see Table 7). The time lapse between the beginning of exposure to cofactor and the onset of death greatly exceeded the duration of the previous immersion of the fish in the prymnesin solution. This implies that the survival times of fish in the cofactor + prymnesin systems probably depended on the time required for the action of cofactor on the prymnesin-sensitized fish, rather than on the time during which the sensitization by prymnesin was accomplished.

Table 6. Influence of prymnesin on ichthyotoxicity of various compounds

\begin{tabular}{|c|c|c|c|}
\hline Compound & $\begin{array}{c}\text { Buffer } \\
\text { (5 mM; pH 8.0) }\end{array}$ & $\begin{array}{l}\mathrm{LD} 100 \text { (mM) of } \\
\text { compound in } \\
\text { absence of } \\
\text { prymnesin }\end{array}$ & $\begin{array}{l}\mathrm{LD} 100(\mathrm{~mm}) \text { of } \\
\text { compound in } \\
\text { presence of } \\
\text { prymnesin } \\
(1 \cdot 0 \text { units } / \mathrm{ml} .)\end{array}$ \\
\hline $\begin{array}{l}\mathrm{CaCl}_{2} \\
\mathrm{Streptomycin} \mathrm{SO}_{4} \\
\mathrm{CaSO}_{4} \\
\mathrm{MgCl}_{2} \\
\mathrm{MgCl}_{2} \\
\mathrm{KCl} \\
\mathrm{NaCl}\end{array}$ & $\begin{array}{l}\mathrm{NaHCO}_{3} \\
\mathrm{NaHCO}_{3} \\
\mathrm{NaHCO}_{3} \\
\mathrm{NaHCO}_{3} \\
\mathrm{Na}_{2} \mathrm{HPO}_{4} \\
\mathrm{Na}_{2} \mathrm{HPO}_{4} \\
\mathrm{Na}_{2} \mathrm{HPO}_{4}\end{array}$ & $\begin{aligned} & 60 \\
& 20 \\
&> 20 \\
& 80 \\
&> 40 \\
&> 20 \\
&> 50\end{aligned}$ & $\begin{array}{r}1 \\
\mathbf{1} \\
\mathbf{5} \\
\mathbf{5} \\
\mathbf{2 0} \\
- \\
-\end{array}$ \\
\hline
\end{tabular}

The LD100 value of prymnesin in the standard assay system was doubled when a solution of prymnesin ( $20 \mathrm{units} / \mathrm{ml}$.) was held for $6 \mathrm{hr}$. at room temperature at about pH 10 before the test was carried out. The solution, thus partially inactivated, was rapidly restored to its original titre by subsequent incubation at $\mathbf{p H} 4 \cdot 0$. Thus there appeared to be at least a qualitative resemblance between the effects of successive exposure to alkali and acid on ichthyotoxicity and haemolytic activity, respectively.

To learn whether plant saponins require cofactor for the manifestation of the lethal effect on fish, methanol-soluble components of a commercial saponin pre- 
paration (British Drug Houses Ltd.) were taken into water and dialysed against dilute acid $\left(10^{-4} \mathrm{~N}\right.$-hydrochloric acid for 3 days). The LD 100 values of the dialysand at $\mathrm{pH} 6.0,7 \cdot 0$ and $8 \cdot 0$, respectively ( $\mathrm{pH}$ adjusted with $0.01 \mathrm{M}$-sodium phosphate), were as follows (in $\mu$ g. original crude preparation $/ \mathrm{ml}$. final system): $250,167,125$. Addition of cofactor $\left(20 \mathrm{mM}-\mathrm{MgCl}_{2}\right)$ to such dialysands did not alter their $\mathrm{LD} 100$ values.
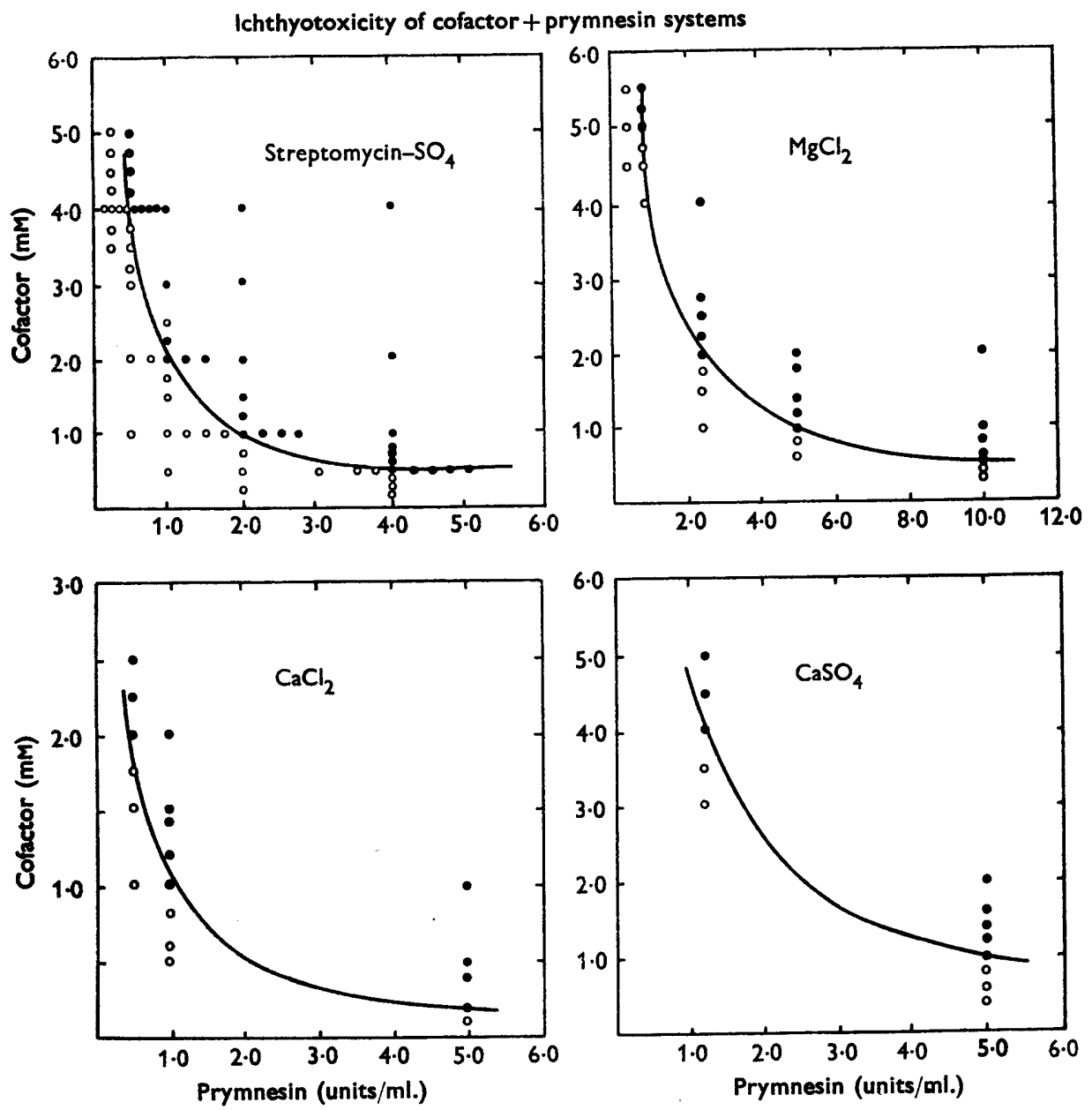

Fig. 3. Ichthyotoxicity of cofactor + prymnesin systems. Test mixtures contained in each case prymnesin and a single added salt under the standard conditions. Fish were exposed to prymnesin at graded dilutions in the presence of a fixed cofactor concentration and to cofactor at graded dilutions in presence of a fixed concentration of prymnesin. Solution mixtures in which one or more of the animals survived for $3 \mathrm{hr}$. are recorded by $O$ and those in which no animal survived by $O$. Drawn curves are calculated from equation (1) on the basis of appropriate values assigned to $Q$ (streptomycin sulphate, 2.0; magnesium chloride, 5.0; calcium chloride, $1 \cdot 0$; calcium sulphate, $5 \cdot 0$ ), concentration of cofactor being expressed in $\mathrm{mm}$ and that of prymnesin in units/ml. of final system. 
Table 7. Effect of prymnesin on the susceptibility of fish to streptomycin sulphate

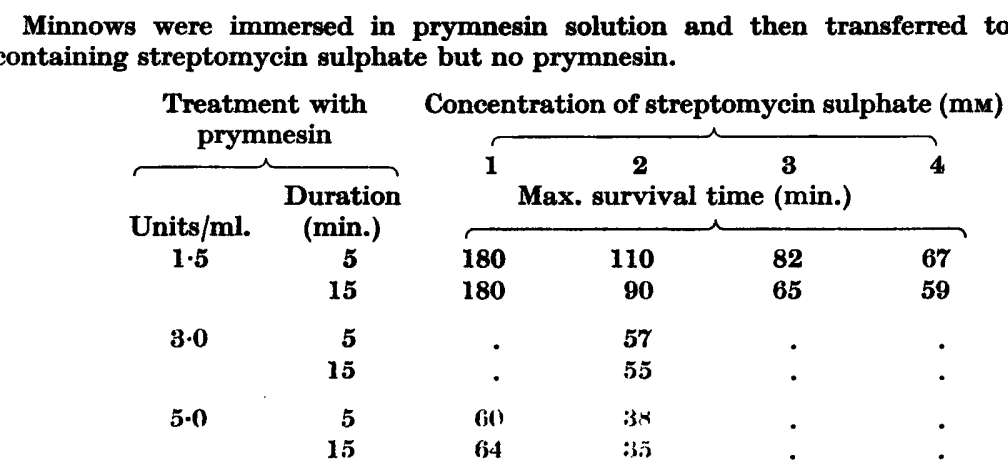

\section{DISCUSSION}

A simple diagnostic procedure to indicate whether prymnesin was the causal agent in any particular outbreak of mass mortality among fish has been sought. Some properties of prymnesin which are disclosed in this paper might be useful in this connexion. They are in particular the non-dialysability of this agent, its rather unusual solubility pattern and its dependence for action after dialysis on an added cofactor. Solubility in methanol and in $n$-propanol water solvent systems distinguishes the toxic material in prymnesin from simple proteins and polysaccharides. The observed properties are consistent with the view that the toxic material is lipid and in which there are present both non-polar and polar moieties, both of which contribute significantly to the over-all behaviour. It has also been noted that the ratio of haemolytic to ichthyotoxic titre in a preparation made from a given starting material tends to maintain nearly a constant value throughout successive stages in purification, but that a wide variation in the activity ratio can be observed as between preparations made from different batches of culture fluid. The results are consistent with the view that a family of compounds possessing a similar basal structure are concerned in the cytotoxic activities of Prymnesium parvum. The homogeneity of even the most potent of our preparations has not been established. Several of the observed properties of the prymnesins (ichthyotoxicity and haemolytic activity, non-dialysability against water, general solubility features, formation of insoluble inactive complexes with certain alcohols, the capacity to undergo precipitation by magnesium hydroxide and ammonium sulphate) are also exhibited by saponins (see Kofler \& Wolkenberg, 1925; Windaus, 1910; Windaus \& Weinhold, 1932). But saponin does not require a cofactor.

Though prymnesin in aqueous solution exhibits the behaviour of a colloid, fish immersed in such a solution are promptly sensitized. The rapidity of the action suggests that the immediate target is an exposed organ, probably the gill. Attention has been directed to the fact that the preparations which manifest ichthyotoxicity also have haemolytic activity. Both cation and anion in a salt + prymnesin system affect the toxicity. Moreover, prymnesin causes fish to become susceptible to poisoning by such widely different compounds as calcium chloride and streptomycin sulphate. To account for these observations the hypothesis can be considered that 
the mode of the action of prymnesin on fish resides in an impairment of the permeability meshanism of the gill.

We are indebted to Dr M. Shilo for advice and criticism and thank Mr S. Sarig for many courtesies. Financial assistance from the Fish Breeders' Association of Israel and a grant-in-aid from the Ford Foundation are gratefully acknowledged. The work presented in this communication was carried out by one of us (J.Y.) in partial fulfilment of requirements for a Ph.D. degree.

\section{REFERENCES}

Berry, H. K. \& CaIN, L. (1949). A paper chromatographic technique for determining excretion of amino acids in presence of interfering substances. Arch. Biochem. 24, 179.

CounIER, B. H. (1951). Factors affecting the haemolytic action of 'lysolecithin' upon rabbit erythrocytes. J. gen. Physiol. 35, 617.

Droop, M. R. (1954). A note on the isolation of small marine algae and flagellates in pure culture. J. mar. Biol. Ass. U.K. 33, 511.

Feigl, F. (1954). Spot Tests, Vol. 2, p. 288 (4th ed.). Amsterdam: Elsevier.

Heftman, E. \& Hayden, A. L. (1952). Paper chromatography of steroid sapogenins and their acetates. J. biol. Chem. 197, 47 .

Kofler, L. \& Wolkenberg, A. (1925). Über das Verhalten von Saponinen bei der Dialyse. Biochem. Z. 160, 398.

Lirebert, F. \& Deerns, W. M. (1920). Onderzoek naar de Oorzaak van een Vischsterfte in den polder Workumer-Nieuwland, Nabij Workum. Verh. Rijksinst. Vissch Onderz. 1, 81.

Otterstrøm, C. V. \& Stegman-Nielsen, E. (1940). Two cases of extensive mortality in fish caused by the flagellate Prymnesium parvum Carter. Rep. Dan. biol. Sta. 44, 5.

Reich, K. \& Aschner, M. (1947). Mass development and control of the phytoflagellate Prymnesium paroum in fish ponds in Palestine. Palestine J. Bot., Jerusalem, 4, 14.

Reich, K. \& KAHN, J. (1954). A bacterial-free culture of Prymnesium parvum (Chrysomonadinae). Bull. Res. Counc. Israel, 4, 144.

ShrLo, M. \& Ascrner, M. (1953). Factors governing the toxicity of cultures containing the phytoflagellate Prymnesium paroum Carter. J. gen. Microbiol. 8, 333.

Shmo, M. \& Rosmanerger, R. (1960). Studies on the toxic principles formed by the chrysomonad Prymnesium paroum Carter. Symposium of the New York Academy of Natural Science (in the Press).

Singre, T. P. \& Krarney, E. B. (1950). The L-amino acid oxidase of snake venom. Arch. Biochem. 29, 190.

StoLt, A. \& KreIs, W. (1951). Neue herzwirksame Glykoside aus der weissen Meerzwiebel. Helv. Chim. Acta, 34, 1432.

Wrndaus, A. (1910). Uber die quantitative Bestimmung des Chloresterins und der Chloresterinester in einigen normalen und pathologischen Nieren. Hoppe-Seyl. Z. 65, 110.

Windaus, A. \& Wrinhom, R. (1932). Über einige Additions-Verbindungen des Digitonins. Hoppe-Seyl. Z. 126, 299.

YARIV, J. (1955). The toxin of Prymnesium parvum. Bull. Res. Coun. Israel, 5A, 96.

YARIV, J. (1958). Toxicity of Prymnesium cultures. Ph.D. thesis, Hebrew University, Jerusalem (Hebrew manuscript). 